\title{
AVALIAÇÃO DA INCORPORAÇÃO DE PEDRA CARIRI EM MASSAS DE TIJOLOS DE CERÂMICA VERMELHA*
}

Antônio Demouthie de Sales Rolim Esmeraldo ${ }^{1}$ Amélia de Santana Cartaxo

\section{Resumo}

As indústrias de cerâmica vermelha têm grande importância na região assim como a mineração e beneficiamento de calcário laminado representam um importante segmento econômico do Estado do Ceará, entretanto produzem uma grande quantidade de resíduos, que poluem e agridem o meio ambiente. Assim, esse trabalho tem por objetivo a caracterização da incorporação do resíduo da Pedra Cariri avaliando sua aplicabilidade como matéria-prima cerâmica alternativa para a produção de telhas cerâmicas. Foram formuladas composições contendo o resíduo e confeccionados corpos-de-prova por prensagem. Os corpos-de-prova foram queimados e, em seguida, foram determinados a cor após a queima, perda ao fogo, retração linear, absorção de água, porosidade aparente e o módulo de ruptura à flexão. Obteve-se uma com avermelhada, com um tom mais claro nas que tiveram a pedra cariri na massa. Também foi visto uma porosidade, juntamente com uma absorção em nível aceitável para tijolos cerâmicos e a tensão de ruptura aumentou em $5 \%$ e decaiu em $10 \%$. Após todos os testes feitos, provou-se que o resíduo tem a possibilidade de ser usado na incorporação de até $5 \%$ de resíduo em formulações para a produção de telhas cerâmicas.

Palavras-chave: Caracterização; Incorporação; Pedra-cariri; Tijolos.

\section{EVALUATION OF INCORPORATION OF PEDRA-CARIRI IN THE RED CERAMIC BRICK MASSES}

\section{Abstract}

The red ceramic industries have great importance in the region as well as the mining and laminated limestone processing represent an important economic sector of the State of Ceará, but produce a lot of waste that pollute and damage the environment. Thus, this study aims to characterize the residue incorporation of Cariri Stone evaluating its applicability as an alternative ceramic raw material for the production of ceramic tiles. compositions were formulated containing the residue and made bodies of the test piece by pressing. The bodies of the test piece were burned and then were determined color after firing, loss on ignition, linear shrinkage, water absorption, apparent porosity and modulus of rupture in bending. We obtained a with red, with a lighter shade on who had the pedra-cariri in weight. It was also seen porosity, together with an acceptable level of water absorption for ceramic bricks and the breakdown stress increased by $5 \%$ and fell by $10 \%$. After all the tests performed, it has been proved that the waste is able to be used for the incorporation of up to $5 \%$ in formulations for the production of ceramic tiles.

Keywords: Characterization; Incorporation; Pedra-cariri; Bricks 


\section{INTRODUÇÃO}

No Brasil, o uso de telhas e tijolos maciços ocorrem desde a época do descobrimento. Inicialmente as telhas eram conformadas de forma manual com mão de obra escrava da época, onde estes as moldavam entre suas pernas. Tal registro pode ser confirmado através de antigas peças que apresentam a forma da estrutura dos ossos humanos (ANICER, 2000).

A principal matéria prima para a produção de blocos e telhas é a argila e as indústrias de cerâmica vermelha empregam duas ou mais argilas para a obtenção de uma massa com as características desejadas. Santos (1989) define a argila como um material natural, terroso, de granulometria bem fina, que geralmente adquire, quando molhada, certa moldabilidade. Segundo a ABC (2002), as argilas para fabricação de cerâmica vermelha devem, de modo geral, ser de fácil destorroamento e permitir uma moldagem adequada; apresentar granulometria bem fina e distribuição granulométrica em equidade (para garantir o controle das dimensões finais do produto).

A mineração é uma atividade que representa um impacto ambiental enorme, e um dos grandes tópicos para o século XXI é a eliminação dos resíduos industriais oriundos das empresas mineradoras. Segundo Mendonça (2006), dentre os impactos gerados pela mineração encontram-se de forma mais evidente: o desmatamento; o assoreamento e/ou erosão de rios e riachos, podendo chegar à alteração do curso dos mesmos; a instabilidade de taludes; a produção de barulho e poeira; alterações do nível de rios; e a modificação do relevo. A mineração da pedra cariri tem acumulado um grande número de resíduos, até por que o processo todo é manual, e gera muitas sobras e lama nas serrarias. A destinação alternativa desse rejeito vem sendo objeto de estudo de vários autores, e tem-se estudado uma melhor maneira de ser reaproveitado. A indústria de cerâmica vermelha é um destino bem promissor para o resíduo.

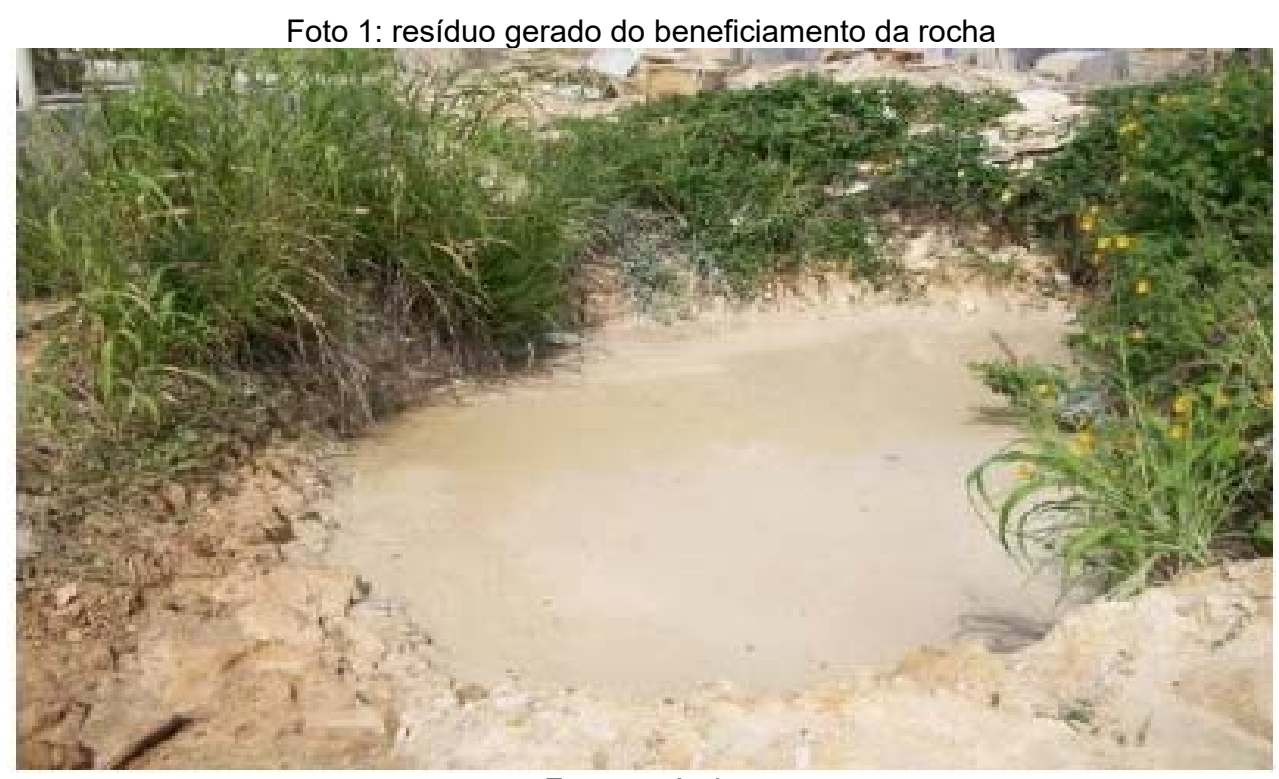

Fonte: própria

Objetivando melhorar as propriedades físicas dos blocos de vedação, foi proposto inserir pedra cariri na formulação do bloco, visando um reaproveitamento desta, tendo em vista que seu resíduo é bem prejudicial ao ambiente. 


\section{MATERIAIS E MÉTODOS}

Para o presente trabalho foram utilizadas amostras de rejeito de pedra cariri colhidos em Nova Olinda - CE e amostra de argila doada por uma cerâmica localizada na cidade de Crato - CE. A pedra cariri e a argila foram secas a $110^{\circ} \mathrm{C}$, desaglomerados em moinho de bolas e peneirados através de peneira ABNT 100 mesh. Em seguida, foram confeccionados corpos-de-prova de $80 \mathrm{~mm}$ x $20 \mathrm{~mm}$ × $5 \mathrm{~mm}$ por prensagem uniaxial a 4 Toneladas. Tais corpos-de-prova foram queimados a $950^{\circ} \mathrm{C}$. Os corposde-prova queimados foram submetidos a ensaio de caracterização física, com determinação da absorção de água, cor após a queima, perda ao fogo, retração linear, porosidade aparente e módulo de ruptura a flexão. Os ensaios cerâmicos foram feitos segundo a metodologia de ensaios preliminares proposta por Barzaghi e Salge (1982) e Souza Santos (1992), para caracterização de matérias-primas para a indústria cerâmica.

\section{RESULTADOS E DISCUSSÃO}

Após os ensaios, foram obtidos os seguintes resultados. A cor após a queima variou com o percentual de pedra cariri colocado, entre um vermelho mais intenso e um vermelho bem mais claro. A cor vermelha na peça é devido a presença de oxido de ferro na amostra e a cor mais clara foi devido a pedra cariri.

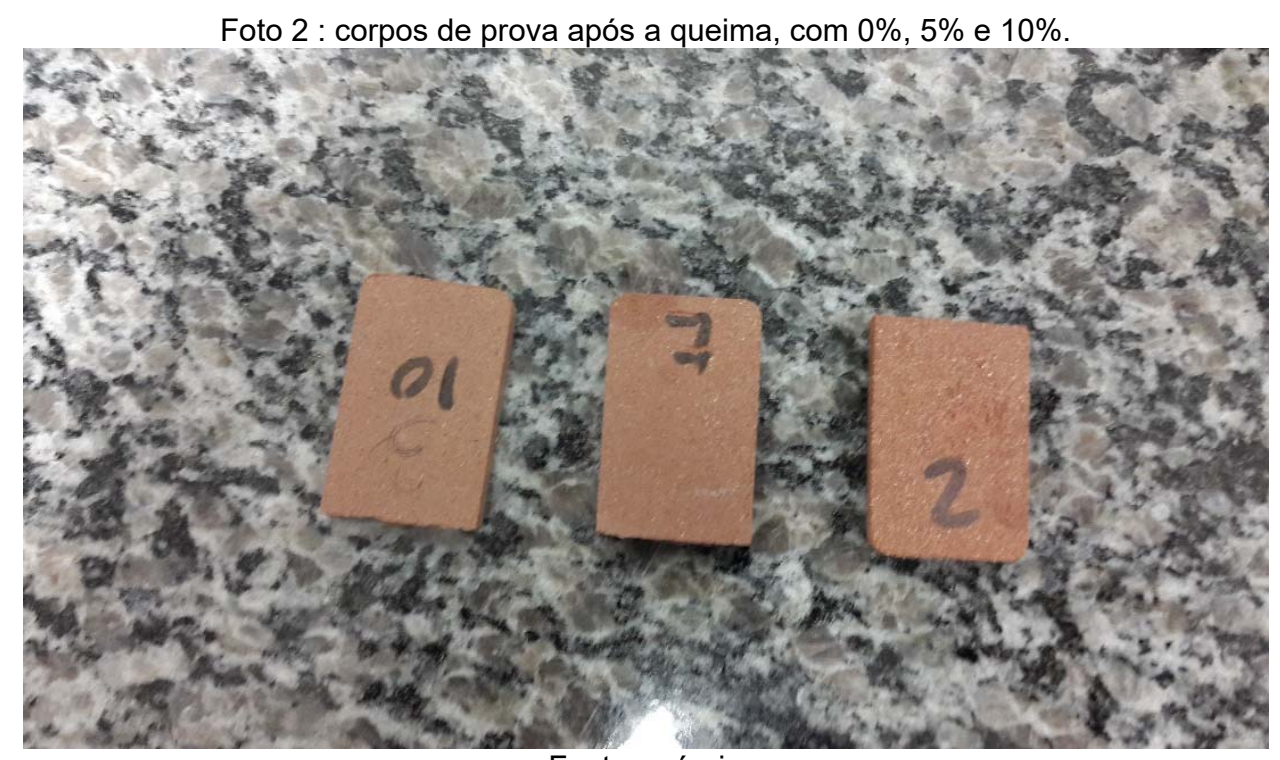

Fonte: própria

Tabela 1: absorção de água

\begin{tabular}{|c|c|}
\hline Absorção de água (24h) & Média (\%) \\
\hline $0 \%$ pedra cariri & 8,83 \\
\hline $5 \%$ pedra cariri & 9,8 \\
\hline $10 \%$ pedra cariri & 10,61 \\
\hline
\end{tabular}

\begin{tabular}{|c|c|}
\hline \multicolumn{2}{|c|}{ Tabela 2: porosidade aparente } \\
\hline Porosidade aparente & Média (\%) \\
\hline 0\% pedra cariri & 9,72 \\
\hline $5 \%$ pedra cariri & 10,83 \\
\hline $10 \%$ pedra cariri & 15,3 \\
\hline
\end{tabular}


A absorção de agua nos corpos de prova aumentou gradualmente de acordo com a quantidade de pedra cariri inserida, o que é comprovado pelo aumento de porosidade nos corpos de prova, que tem como causa a liberação de gases de decomposição do carbonato de cálcio presente na pedra cariri (ESMERALDO et al, 2015).

\begin{tabular}{|c|c|}
\hline \multicolumn{1}{|c|}{ Tabela 3: perda ao fogo } \\
\hline Perda ao fogo & Média (\%) \\
\hline 0\% pedra cariri & 7,28 \\
\hline $5 \%$ pedra cariri & 13,78 \\
\hline $10 \%$ pedra cariri & 16 \\
\hline
\end{tabular}

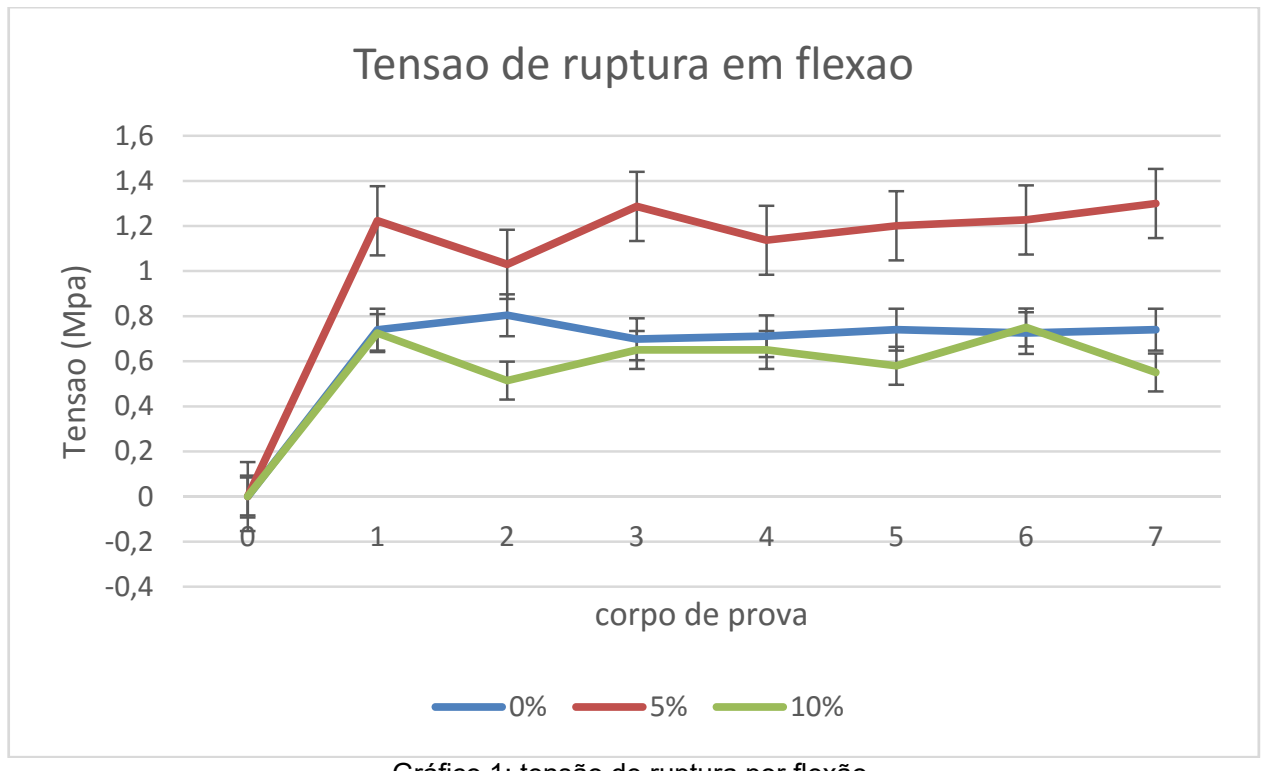

Gráfico 1: tensão de ruptura por flexão.

A tensão de ruptura teve um pequeno incremento com o percentual de 5 por cento da pedra cariri e uma queda enorme com 10 por cento. A maior compactação causada pela adição de pedra cariri não superou o efeito negativo da geração de gases de decomposição do carbonato de cálcio, que fragilizou a estrutura pela abertura de poros. A grande perda ao fogo se deu pela liberação de gases da pedra cariri em queimas superiores a $900^{\circ} \mathrm{C}$. Não houve retração linear apreciável nos corpos de prova, a sílica presente deu uma boa estabilidade dimensional, juntamente com o calcário laminado (ESMERALDO Et al, 2015).

\section{CONCLUSÃO}

Após a realização dos testes, provou-se a viabilidade do uso da pedra cariri como enchimento nas massas para fabricação de tijolos cerâmicos em teores até $5 \% \mathrm{em}$ peso, que dará um aumento na resistência do mesmo, alterando minimamente as outras propriedades físicas necessárias para tal finalidade.

\section{REFERÊNCIAS}

1 SANTOS, P. S., Ciência e tecnologia de argilas. (3. Ed.). São Paulo: Edgard Blücher, 1992, v. 1. 408p

2 BARZAGHI, L., SALGE, A. Resistência à flexão e moldagem de argilas. Cerâmica, v. 28, n. 151, p. 15-17, 1982. 
3 MENDONÇA, L. A. R., Diagnóstico ambiental preliminar de áreas de mineração de calcário nos municípios de Santana do Cariri, Nova Olinda, Farias Brito e Altaneira, no Sul do Estado do Ceará. Juazeiro do Norte: CENTEC (Instituto Centro de Ensino Tecnológico), 40p. 2006

4 GRIMMER, A.; WILLIANS, P. K. A brief history of clay roofing tile. Disponível em: http://www.mca-tile.com/history Acesso em: 23 dez. 2015.

5 ESMERALDO, A. D. S. R.; CARTAXO, A. S.; VIEIRA, F. M.; MAFRA, J. V. B.; SILVA, J. H.; BARROSO, M. D. B.. Avaliação do uso de resíduo de pedra cariri na composição de massas cerâmicas para blocos de vedação. In: ABM WEEK, 2015, Rio de Janeiro. CONGRESSO ANUAL DA ABM - INTERNACIONAL. São Paulo: Associação Brasileira de Metalurgia, Materiais e Mineração, 2015. v. 70. 